mitral anulus. The tricuspid valve was repaired by annular plication and leaflet suture.

The postoperative course was uneventful. A transesophageal echocardiogram 2 weeks later showed narrow mitral regurgitation located at the level of the anterior commissure and extending along the anterior leaflet (Fig. 2 ), with normal function in the area of the reconstructed posterior commissure, a mean transmitral gradient of 8 $\mathrm{mm} \mathrm{Hg}$, and a calculated surface area of $1.95 \mathrm{~cm}^{2}$. The tricuspid valve had a mild to moderate leak.

Although many questions remain unanswered with this type of repair, use of the posterior leaflet of the tricuspid valve may be helpful for mitral repair.

\section{REFERENCES}

1. Carpentier A. Cardiac valve surgery-the "French correction." J Thorac CARDIOVASC SuRg 1983;86:32337.
2. Hvass U, Pansard Y, Lamberti A, et al. Réparations de lésions mitrales rhumatismales par transfert d'un segment de la valve posterieure avec ses cordages sur la valve anterieure. Arch Mal Coeur 1986;1: 103-6.

3. David TE, Boss J, Rakowski H. Mitral valve repair by replacement of chordae tendinae with polytertrafluoroethylene sutures. J THORAC CARDIOvasc SuRg 1991;101: 495-501.

4. Pellerin M, Chauvaud S, Chachques JC, Carpentier A. Mitral leaflet extension with glutaraldehyde treated autologous pericardium. Presented at the Sixth International Symposium on Cardiac Bioprostheses. Vancouver, BC, Canada. July 29-31, 1994.

5. Acar C, Farge A, Ramsheyi A, et al. Mitral valve replacement using a cryopreserved mitral homograft. Ann Thorac Surg 1994;57:746-8.

\title{
SUCCESSFUL TREATMENT OF LIFE-THREATENING ACUTE REPERFUSION INJURY AFTER LUNG TRANSPLANTATION WITH INHALED NITRIC OXIDE
}

\author{
P. Macdonald, FRACP, PhD, J. Mundy, FRACS, P. Rogers, BSc, G. Harrison, FRANZCA, J. Branch, FRANZCA, \\ A. Glanville, FRACP, MD, A. Keogh, FRACP, MD, and P. Spratt, FRACS, FRCS(Edin), Darlinghurst, Australia
}

\footnotetext{
Acute reperfusion injury is a potentially life-threatening complication of lung transplantation. Typically, acute reperfusion injury becomes apparent within hours of completion of the transplant procedure and in its most severe form results in progressive hypoxemia, pulmonary hypertension, systemic hypotension, and diffuse opacification of the transplanted lung or lungs on chest x-ray films, a clinical syndrome known as the reimplantation response. ${ }^{1}$ The pathophysiologic disturbance and clinical picture of acute reperfusion injury closely resembles adult respiratory distress syndrome (ARDS), a condition that has been successfully treated with inhaled nitric oxide (iNO). ${ }^{2}$ In this report we describe two cases of severe acute reperfusion injury after lung transplantation that were treated with iNO. In both cases, iNO rapidly reversed the respiratory failure and associated hemodynamic abnormalities.

Case 1. A 50-year-old woman underwent left single lung transplantation because of smoking-induced emphysema on December 31, 1993. The donor was a 22-year-old woman who died after craniotomy. Arterial oxygen tension $\left(\mathrm{PaO}_{2}\right)$ to inspired oxygen fraction $\left(\mathrm{FiO}_{2}\right)$ ratio was

From the Cardiopuimonary Transplant Unit, St. Vincent's Hospital, Darlinghurst, New South Wales, Australia.

J Thorac Cardiovasc Surg 1995;110:861-3

Copyright $\odot 1995$ by Mosby-Year Book, Inc.

$0022-5223 / 95 \$ 5.00+0 \quad \mathbf{1 2 / 5 4 / 6 2 8 3 7}$
}

$388 \mathrm{~mm} \mathrm{Hg}$ before procurement. The ischemic time for the donor lung was 384 minutes. The initial postoperative $\mathrm{PaO}_{2} / \mathrm{FiO}_{2}$ ratio was $216 \mathrm{~mm} \mathrm{Hg}$. A chest x-ray film taken 1 hour after operation showed full expansion of the transplanted lung with no radiologic infiltrate. The patient was extubated at 12 hours after operation. During the next 45 minutes increasing dyspnea occurred. A repeat chest $\mathrm{x}$-ray film showed diffuse opacification of the transplanted lung. Shortly after the film was obtained the patient had cardiorespiratory arrest. She required prolonged resuscitation before a stable cardiac rhythm could be reestablished and she remained critically ill during the next 6 hours with profound hypoxemia $\left(\mathrm{PaO}_{2} / \mathrm{FiO}_{2}\right.$ ratio in the range of 70 to $80 \mathrm{~mm} \mathrm{Hg}$ ) and shock (mean systemic blood pressure between 45 and $55 \mathrm{~mm} \mathrm{Hg}$ with severe oliguria) despite intravenous infusions of high-dose adrenaline and noradrenaline. Mean pulmonary artery wedge pressure remained in the range of 10 to $14 \mathrm{~mm} \mathrm{Hg}$ but pulmonary vascular resistance (PVR) was markedly elevated (calculated mean PVR in the range of 350 to 400 dynes $\cdot \mathrm{sec} \cdot \mathrm{cm}^{-5}$ ). Administration of iNO was begun at an inspired concentration of $36 \mathrm{ppm}$. NO was added at the ventilator end of the inspiratory limb of a Servo $900 \mathrm{C}$ ventilator (Siemens, Solna, Sweden). Within the next 15 minutes $\mathrm{PaO}_{2}$ rose from 73 to $103 \mathrm{~mm} \mathrm{Hg}$ and within 1 hour this value rose to $212 \mathrm{~mm} \mathrm{Hg}$. Hemodynamic changes in response to iNO are summarized in Table I. An attempt to wean the patient from iNO after 12 hours of administration was associated with an abrupt fall in 
Table I. $\mathrm{PaO}_{2} / \mathrm{FiO}_{2}$ ratio and hemodynamic variables for the two patients before and during administration of $i N O$

\begin{tabular}{lrcrr}
\hline & Pre & \multicolumn{3}{c}{ Post iNO } \\
\cline { 3 - 5 } & $i N O$ & 15 min & $1 \mathrm{hr}$ & $24 \mathrm{hr}$ \\
\hline $\mathrm{PaO}_{2} / \mathrm{FiO}_{2}$ ratio $(\mathrm{mm} \mathrm{Hg})$ & 73 & 103 & 212 & 192 \\
& 57 & 130 & 150 & 213 \\
$\mathrm{MPAP}(\mathrm{mm} \mathrm{Hg})$ & 33 & 24 & 22 & 19 \\
& 29 & 26 & 20 & 10 \\
$\mathrm{MPAWP}(\mathrm{mm} \mathrm{Hg})$ & 14 & 10 & 9 & 9 \\
& 11 & 14 & 8 & 3 \\
$\mathrm{MAP}(\mathrm{mm} \mathrm{Hg})$ & 54 & 62 & 68 & 69 \\
& 59 & 73 & 73 & 73 \\
$\mathrm{PVR}\left(\right.$ dynes $\cdot \mathrm{sec} \cdot \mathrm{cm}^{-5}$ ) & 389 & 294 & 231 & 170 \\
& 599 & 355 & 309 & 200 \\
$\mathrm{SVR}\left(\right.$ dynes $\cdot \mathrm{sec} \cdot \mathrm{cm}^{-5}$ ) & 1045 & 1241 & 1154 & 1122 \\
& 1831 & 2042 & 1804 & 1798 \\
\hline
\end{tabular}

Pre iNO, Before administration of iNO; Post iNO, after iNO administration was begun; $M P A P$, mean pulmonary artery pressure; $M P A W P$, mean pulmonary artery wedge pressure; $M A P$, mean systemic arterial pressure; $S V R$, systemic vascular resistance.

$\mathrm{PaO}_{2}$ from 103 to $77 \mathrm{~mm} \mathrm{Hg}$ and rise in PVR from 170 to 315 dynes $\cdot \mathrm{sec} \cdot \mathrm{cm}^{-5}$, which was reversed by reinstitution of iNO administration at $20 \mathrm{ppm}$. The patient was able to be weaned completely from iNO administration after 26 hours. By this time, the $\mathrm{PaO}_{2} / \mathrm{FiO}_{2}$ ratio was $192 \mathrm{~mm} \mathrm{Hg}$ and the opacification in the transplanted lung noted on the previous chest $x$-ray film had largely cleared.

Case 2. A 29-year-old woman with cystic bronchiectasis underwent bilateral sequential single-lung transplantation on May 26, 1994. The donor was a 55-year-old man who died of spontaneous intracerebral hemorrhage. The $\mathrm{PaO}_{2} /$ $\mathrm{FiO}_{2}$ ratio was $342 \mathrm{~mm} \mathrm{Hg}$ when measured before lung procurement. The right lung was transplanted first without incident. The ischemic time for the right lung was 210 minutes. During implantation of the left lung, 10 minutes after reperfusion of the right lung, progressive hypoxemia and hypotension ensued. Cardiopulmonary bypass was established and implantation of the left lung completed. The ischemic time for the left lung was 330 minutes. After reperfusion of the left lung and weaning from cardiopulmonary bypass hypoxemia and hypotension again occurred. The patient was transferred to the intensive care unit but her condition continued to deteriorate. Intravenous noradrenaline administration was begun because of worsening systemic hypotension. A chest $x$-ray film showed diffuse opacification of the right lung with less marked changes in the left lung. A diagnosis of acute reperfusion injury was made and iNO administration was begun in a concentration of $10 \mathrm{ppm}$. As in the first case there was evidence of improvement within 15 minutes of the start of iNO administration with a rise in $\mathrm{PaO}_{2}$ from 57 $\mathrm{mm} \mathrm{Hg}$ to $130 \mathrm{~mm} \mathrm{Hg}$. One hour after iNO administration began, the $\mathrm{PaO}_{2} / \mathrm{FiO}_{2}$ ratio had risen from 57 to 150 $\mathrm{mm} \mathrm{Hg}$ and the pulmonary vascular resistance had fallen from 599 to 309 dynes $\cdot \mathrm{sec} \cdot \mathrm{cm}^{-5}$ (Table I). The respiratory and hemodynamic parameters remained stable there- after until an accidental increase in the concentration of iNO, which occurred after 18 hours of administration. The patient received an inhaled concentration of NO of 110 ppm for a period of approximately 30 minutes and became nauseated and restless. The methemoglobin level at this time was $19 \%$. The administration of iNO was temporarily discontinued and the $\mathrm{FiO}_{2}$ increased to 0.85 . Administration of iNO was recommenced at $10 \mathrm{ppm}$ after 1 hour at which time the methemoglobin level had fallen to $13 \%$. The methemoglobin level continued to fall exponentially during the next 5 hours. The iNO was withdrawn completely after 24 hours of administration. The patient was extubated 54 hours after operation.

Discussion. Acute reperfusion injury of the lung is characterized by increased pulmonary capillary permeability, pulmonary edema, and an acute rise in PVR. The latter abnormality has been found to be largely a result of a loss of endothelium-dependent NO-mediated relaxation. ${ }^{3}$ In its most severe form, acute reperfusion injury results in ARDS. Both patients were critically ill at the time of introduction of iNO. Administration of iNO led to a rapid and dramatic improvement in lung function and stabilization of the circulation. The mechanism of the beneficial effect of iNO in. acute reperfusion injury is likely to be similar to that seen in ARDS and related to two unique pharmacokinetic properties of iNO. First, iNO is only delivered to ventilated lung segments so that its vasodilator effect is confined to these segments, which thereby optimizes ventilation-perfusion matching. ${ }^{2}$ Second, NO is rapidly inactivated after its diffusion into the bloodstream by binding to hemoglobin, ${ }^{4}$ which prevents any systemic effect of the gas.

Recently, Adatia and associates ${ }^{5}$ reported the use of iNO in the treatment of six patients with postoperative graft dysfunction after lung transplantation. They observed an average fall in PVR of $31 \%$ and a trend toward increased $\mathrm{PaO}_{2}$ in response to a 15 -minute administration of $80 \mathrm{ppm}$ iNO. Two of their patients had hypoxemia refractory to conventional treatment. Both showed a marked improvement in $\mathrm{PaO}_{2}$ in response to iNO, which was continued in low dosages for 40 and 69 hours, respectively. The dosage of iNO chosen in our first case was based on early studies in human beings in which a dose of $36 \mathrm{ppm}$ was used. ${ }^{2}$ In 10 patients awaiting cardiac transplantation, we observed no difference in the pulmonary vasodilator response between 10 and $40 \mathrm{ppm}$ iNO (unpublished observations). For this reason we chose a dosage of $10 \mathrm{ppm}$ iNO in the second case. The rapid development of methemoglobinemia in the second case highlights the potential toxicity of iNO therapy. ${ }^{6}$ We did not observe any major sequelae after the accidental increase in iNO concentration, but the episode emphasizes the need for continuous monitoring of the iNO concentration and methemoglobin level during iNO therapy.

In conclusion, iNO rapidly reversed respiratory failure and shock in two patients who had severe acute reperfusion injury after lung transplantation, and we recommend that this therapy be considered for any patient who has this life-threatening complication after lung transplantation. 


\section{REFERENCES}

1. Siegelman SS, Sinha SBP, Veith FJ. Pulmonary reimplantation response. Ann Surg 1973;177:30-6.

2. Rossaint R, Falke KJ, Lopez F, Slama K, Pison U, Zapol WM. Inhaled nitric oxide for the adult respiratory distress syndrome. N Engl J Med 1993;328:399-405.

3. Fullerton DA, Mitchell MB, McIntyre MC, et al. Cold ischemia and reperfusion each produce pulmonary vasomotor dysfunction in the transplanted lung. J Thorac Cardiovasc Surg 1993;106:1213-7.
4. Rimar S, Gillis N. Selective pulmonary vasodilation by inhaled nitric oxide is due to hemoglobin inactivation. Circulation 1993;88:2884-7.

5. Adatia I, Lillehei C, Arnold $\mathrm{JH}$, et al. Inhaled nitric oxide in the treatment of postoperative graft dysfunction after lung transplantation. Ann Thorac Surg 1994; 57:1311-8.

6. Zapol WM, Rimar S, Gillis N, Marletta M, Bosken CH. Nitric oxide and the lung. Am J Respir Crit Care Med 1994;149:1375-80.

\title{
PSEUDOANEURYSM OF THE BRACHIOCEPHALIC ARTERY CAUSED BY BLUNT CHEST TRAUMA
}

\author{
B. de Jose Maria, MD, ${ }^{a}$ C. Gomar, MD, ${ }^{a}$ C. Mestres, MD, ${ }^{b}$ V. Sorribes, MD, ${ }^{c}$ V. Moral, MD, ${ }^{c}$ and X. Sala, MD, ${ }^{a}$ \\ Barcelona, Spain
}

A 25-year-old man was admitted to a community hospital after a car accident with blunt chest trauma and left-sided hemopneumothorax without rib fractures. Results of laboratory tests were normal on admission, but the chest $x$-ray film showed a widened mediastinum. He was therefore transferred to our hospital. On arrival he had hemodynamic and respiratory impairment with cardiac arrest, from which he was successfully resuscitated. Computed tomography (CT) was performed and showed patent mediastinal vessels with increased density of the upper mediastinum and narrowing of the tracheal lumen. A fiberoptic bronchoscope was then inserted and showed a $50 \%$ extrinsic compression of the distal trachea. Several hours later, in the intensive care unit, the patient had a new hemodynamic impairment with edema of the neck and left arm. A second CT scan then revealed an important hematoma in the upper mediastinum and enlargement of the origin of the brachiocephalic artery. Because of suspected brachiocephalic artery rupture, emergency surgery was performed.

Once a median sternotomy approach was achieved, a contained rupture of the brachiocephalic artery from its origin to its bifurcation was made evident (Fig. 1). The injury was repaired with a $6 \mathrm{~mm}$ polytetrafluorethylene interposition graft (Fig. 2). Intraoperatively, the patient had an unexpected cardiac arrest, and when internal heart compressions were applied, a herniation of the left ventricle through a posterior pericardial rupture was detected, and was thought to be the cause of the cardiac arrest. The pericardium was sutured during resuscitation, and the operation was successfully completed. The patient

From the Departments of Anesthesiology and Cardiovascular Surgery, ${ }^{\mathrm{b}}$ Hospital Clínic de Barcelona, and the Department of Anesthesiology, ${ }^{\mathrm{c}}$ Hospital de Sabadell, Barcelona, Spain.

J Thorac Cardiovasc Surg 1995;110:863-5

Copyright (C) 1995 by Mosby-Year Book, Inc.

$0022-5223 / 95 \$ 5.00+0 \quad \mathbf{1 2 / 8 / 6 0 3 7 8}$ was discharged 20 days after the operation and 18 months later remains free of symptoms.

High-speed car accidents are the major cause of thoracic injuries resulting in disruption of the thoracic aorta and its major branches. The mechanism of injury was first described by Binet and associates ${ }^{1}$ in 1962 . They postulated that an anteroposterior force applied to the chest decreases the distance between the sternum and vertebral spine, thus displacing the heart backward and to the left. This increases the curvature of the aortic arch and stretches the vessels. The patient so injured usually hyperextends the cervical spine and rotates the head. This places further tension on the carotid artery opposite the side of rotation, resulting in an avulsion of the brachiocephalic artery from the aorta. This type of injury most often occurs at the aortic isthmus, although the brachiocephalic artery is the second most common site of vascular injury in chest trauma. In blunt trauma, the proximal artery is the more commonly injured.

It has been classically accepted that fractures of the first or second rib (or both) are an indicator of potential serious injury to adjacent neurovascular structures. ${ }^{2} \mathrm{Nev}-$ ertheless, more recent studies $^{3}$ have proved that the presence of first or second rib fractures, or even multiple rib fractures, is not associated with an increased risk of injury to the thoracic great vessels.

Even though associated injuries are common in polytrauma, cardiac or other vessel injuries are rarely associated with brachiocephalic artery disruption. ${ }^{4}$ In this case, a pericardial rupture causing cardiac herniation and intraoperative cardiac arrest was associated with a brachiocephalic artery aneurysm. Its diagnosis can be difficult, as in the case we report, in which it was overlooked and delayed until the surgical exposure of the mediastinum. Moreover, the repair of such an injury could have been fatally delayed if the operative approach had not been a median sternotomy, which enabled direct manual heart compressions. 